\title{
D.Ç.P: Wordpress Eklentisi Olarak Geliştirilmiş Açık Kaynak Kodlu Bir Ders Çizelgeleme Programı
}

\author{
Muhammed Ömer Faruk SELVİ ${ }^{\mathrm{a}, 1}$, Gizem ORTAÇ, ${ }^{\mathrm{b}, 2 *}$, Turgay Tugay BILLGINN ${ }^{\mathrm{a}, 3}$ \\ a Bursa Teknik Üniversitesi, Doğa Bilimleri ve Mühendislik Fakültesi, Bilgisayar Mühendisliği Bölümü, Bursa, Türkiye \\ b Bursa Teknik Üniversitesi, Rektörlük, Bursa, Türkiye
}

İstanbul Sabahattin Zaim Üniversitesi Fen Bilimleri Enstitüsü Dergisi (2021) 3 (1): 86-93

https://doi.org/10.47769/izufbed.874539

(iD) $O R C I D{ }_{1}^{1} 0000-0002-9523-1789 ;{ }^{2} 0000-0003-1228-9852 ;{ }^{3} 0000-0002-9245-5728$

\begin{tabular}{l}
\hline YAYIN BİLGİSI \\
\hline Yayın geçmişi: \\
Gönderilen tarih: 05 Şubat 2021 \\
Kabul tarihi: 28 Mart 2021 \\
\end{tabular}

Anahtar kelimeler:

Açık kaynak yazılım

Ders porgram 1

Zaman Çizelgesi

Wordpress eklentisi

\begin{abstract}
ÖZET
Eğitim kurumlarında tüm kısıtlamarın karşılandığı bir ders programı çizelgesi hazırlamak oldukça yorucu ve zaman alıcı bir süreçtir. Otomatikleştirilmiş ders programı çizelgesi oluşturma yazılımları yöneticilere zaman kazandırsa da her eğitim kurumunun birbirinden farklı ve sürekli değişen gereksinimleri vardır. Bu nedenle bu çalışmada bir devlet üniversitesinin ders programı hazırlanmasında görevli kişilerin, ortak bir platform üzerinden rahatlıkla öğretim üyesi, sınıf ve ders bilgilerini ulaşıp; çakışma gibi çeşitli sorunları en aza indirerek optimum ders programını hazırlaması amaçlanmıştır. Açık kaynak kodla geliştirilen bu program, eğitim kurumlarının özel ihtiyaçlarına göre değiştirilip kullanılabilmektedir.
\end{abstract}

\section{D.Ç.P: An Open Source Course Scheduling Program Developed as a Wordpress Plugin}

ARTICLE INFO
Article history:
Received: 05 February 2021
Accepted: 28 March 2021

Key words:

Open source software

Syllabus

Timeline

Wordpress plugin

\section{ABSTRACT}

Preparing a curriculum schedule in which all the restrictions are met in educational institutions is a very tiring and time consuming process. Although automated syllabus scheduling software saves time for administrators, each educational institution has different and constantly changing requirements. For this reason, in this study, people in charge of preparing the curriculum of a state university can easily access faculty, class and course information through a common platform; It is aimed to prepare the optimum syllabus by minimizing various problems such as conflict. Developed with open source code, this program can be modified and used according to the special needs of educational institutions.

\section{Giriș}

Eğitim kurumlarında en yaygın olarak kullanılan akademik planlama problemlerinden biri ders çizelgesi hazırlama işlemidir. Eğitimciler, öğrenciler, sınıflar ve öğretmeöğrenme yardımcıları gibi kaynakları çeşitli kısıtlamalara uygun olacak şekilde birleştiren bir çizelge hazırlanması zaman alıcı ve dikkat gerektiren bir süreçtir (Poddar, \& Mondal, 2018).
Bir üniversitede ders programı oluşturulurken çok çeşitli kısıtlamalar bulunmaktadır. Bu nedenle, üniversiteler çeşitli görevler için kendi yazılımlarını geliştirebilecek alt yapıya sahip olsa da; ders çizelgesi planlamasının çeşitli algoritmalar kullanılarak tamamen otomatikleştirilmesi mümkün olmayabilmektedir. Zaman çizelgesi planlamasına dâhil olanların birbiriyle çelişen tercihleri vardır. Bu durum da en uygun çözüm arayışını NP-zor bir sorun haline getirir. Aynı

\footnotetext{
*Sorumlu yazar: gizem.ortac@btu.edu.tr
} 
öğretim üyesi tarafından verilen derslerin ve aynı sınıfı gerektiren derslerin farklı zaman aralıklarında planlanması gerektiği açıktır. Ayrıca, belirli bir öğrenci veya öğrenci grubu, bir müfredat tarafindan bir sömestr boyunca aynı anda iki farklı ancak ilgili dersi almak zorunda kalabilir. Bu gibi durumlarda da derslerin çatışmaları önleyecek şekilde planlanması gerekir. Kısacası bir eğitim kurumu çizelgesi geliştirmek öğretim üyelerinin gereksinimleri, her öğretim üyesinin mevcudiyeti, zaman çizelgesi ve tercihleri, sınıf mevcudiyeti, öğrenci sayısı, sınıf sayısı ve müfredatlar vb. dâhil tüm parametrelerin başarılı bir birleşimini bulmayı gerektiren karmaşık bir sorundur (Rao, Prasad, \& Anusha, 2019).

Ders çizelgesi oluşturma, bir programlama sorunu olarak yaygın bir problemdir. Ayrıca her kurumun kendine özgü özel bir ders çizelgesi biçimi bulunabilmektedir. Yüzlerce hatta binlerce öğrencinin bulunduğu, aynı zamanda farklı büyüklükte ve kapasitede sınıfların yer aldığı üniversitelerde, ortak öğrenciye sahip derslerin çakışmadığı bir çözüm bulunması çoğunlukla mevcut değildir. Bu basitçe, öğrencinin çakışan dersler arasında seçim yapması gerektiği anlamına gelmektedir (Burke, Elliman, \& Weare, 1994).

$\mathrm{Bu}$ çalışmada, Bursa Teknik Üniversitesi Mühendislik ve Doğa Bilimleri Fakültesi için ders çizelgesi hazırlama sorunuyla ilgilenilmiştir. Uygulamanın kullanıldığı üniversitede her y1l öğrenci sayısı ve öğretim üyesi sayısı artsa da dersliklerin sayısı sabit kalmıştır. Ayrıca müfredatlara eklenen yeni dersler ile makul bir ders çizelgesi hazırlamak giderek zor bir hale gelmiştir. Öte yandan fakültede yer alan bölümlerin ortak ders sayısı oldukça fazladır. $\mathrm{Bu}$ ortak derslerin planlanması oldukça zordur. Ek olarak öğretim üyeleri kendi bölümleri haricindeki bölümlere de ders verebilmektedir. Bu sebeple öğretim üyelerinin ve her iki bölümün ders çizelgesi çakışma durumuna karşı dikkatle hazırlanmalıdır. Tüm bu kısıtların üstesinden gelerek en ideal ders programını hazırlamak için Ders Çizelgeleme Programı (DÇP) ismi verilen bir uygulama geliştirilmiştir.

\section{Materyal ve Yöntem}

\subsection{Uygulama hakkında}

DÇP, Fotis Kokkoras ve Antonis Roussos tarafindan tasarlanan açık kaynaklı bir Wordpress eklentisi UniTimetable uygulaması temel alınarak geliştirilmiştir (Kokkoras \& Roussos, t.y). Ücretsiz ve açık kaynaklı bir web yazılım aracı ve PHP - MySQL tabanlı bir içerik yönetim sistemi olan Wordpress internette kullanılan en yaygın sistemler arasındadır. Wordpress, hem geliştiriciler hem de web sitesi yöneticileri için güvenli ve kullanımı kolay programlama yazılımı sağlamaktadır. Ayrıca kaynak kodu optimizasyonuna katkıda bulunan binlerce geliştiricisi bulunmaktadır (Fragulis, Lazaridis, Papatsimouli, \& Skordas, 2018).

Geliştirilen uygulamada Öğretim Üyeleri, Dönemler, Ders Tanımlama, Şubeler, Ders Birleştirme, Sınıflar ve Takvim adı verilen farklı modüller bulunmaktadır. Uygulama sayesinde dersler, bir dönem boyunca belirli bir zamanda planlanabilir. Program dişı etkinlikler ve tatiller de desteklenmektedir. Fakültedeki her bir öğretim üyesi ve açılan derslerin bilgileri tek bir platformda toplanmaktadır. Bölümlerin ders programı hazırlama görevlileri birbirleriyle iletişim kurma zorunluluğundan kurtularak bu platform ile tüm öğretim üyelerinin, dersliklerin, bölümlerin ders çizelgesini filtreleyerek görebilmektedir. Aynı zamanda bu yazılım ile öğretim üyesi ve derslik çakışmaları tespit edilerek kullanıcılara hata mesajı gönderilmektedir. Dersleri gruplara bölmeyi sağlayan şube tanımlamaları da yapılabilmektedir.

\subsection{Uygulama kısıtları}

DÇP ile fakülte bünyesindeki her bölüm için görevlendirilen kullanıcılar kendi bölümleri açısından kısıtlamaları karşılayacak en uygun ders çizelgesini hazırlayabilmektedir. Bu kısıtlamalardan zorunlu olanları genel hatlarıyla aşağıdaki gibi suralanabilir:

1. Her bölümdeki mevcut dersler yarıyıla kayıtlı öğrencilerin katılabilmesi için farklı saatlerde yapılmalıdır.

2. Bir derslikte aynı saatte birden fazla ders yapılamaz.

3. Her öğretim üyesinin, herhangi bir ders zamanında, tek bir derslikte en fazla bir dersi olabilir. Bu nedenle geliştirilen ders çizelgesi bir öğretim üyesinin aynı anda iki farklı ders verebilme olasılığını da içermemelidir.

4. Teori dersleri ilgili sınıflarda, eşdeğer donanım gerektiren laboratuvar dersleri ise ilgili laboratuvarlarda yapılmalıdır.

5. Her ders, kayıtlı öğrenci sayısından daha küçük kapasiteye sahip bir sinıfta yapılamaz.

6. Diğer bölümlere ders veren öğretim üyelerinin dersleri planlanırken her iki bölümün ders çizelgesi ve öğretim üyesinin haftalık ders çizelgesi göz önünde bulundurulmalıdır. 7. Farklı bölümlerin ögrencileri tarafından alınacak yani birleştirilecek dersler çakışma kontrolü dışında tutulmalıdır.

8. Birleştirilen dersler o dersi alan öğrencilerin bulunduğu tüm bölümlerin takviminde gösterilmelidir.

Öte yandan ders çizelgesinde esnek kısıtlamalar da bulunmaktadır. Hafif kısıtlamaların gerçekleştirilme oranı ders çizelgesinden memnuniyet oranını arttırmaktadır. $\mathrm{Bu}$ kısıtlamalar ise aşağıdaki gibi sıralanabilir:

1. Her öğretim üyesinin belirli günler ve ders saatleri için tercihleri,

2. Öğrencilerin tercihleri,

3. Daha az sayıda kayıtlı öğrencinin olduğu derslerin daha küçük kapasiteye sahip sınıflarda yapılması

4. Haftada birkaç saat süren derslerin aynı gün değil farklı günlerde yapılmasıdır.

\subsection{Eklenti kurulumu ve aktivasyonu}

DÇP uygulaması, PHP betiklerinin ilgili Wordpress dizinine (/wp-contents/plugins) aktarılmas1 ve veritabanı tablolarının MySQL veya MariaDB gibi bir veritabanına yüklenmesi sonrasında kullanıma hazır hale gelmektedir.

\subsection{Kullanıcı yetkileri}

DÇP'nin Wordpress eklentisi olarak geliştirilmesi kullanıcı yönetimi ve yetkilendirme problemleri için hızlı, kolay ve güvenli bir çözüm olmuştur. DÇP'de yönetici ve ders programı hazırlama komisyonu üyesi olmak üzere iki farklı kullanıc1 tipi bulunmaktadır. Her komisyon üyesi kendi bölümüne ait öğretim elemanlarını ve dersleri sisteme 
tanımlayıp ortak takvimde uygun bir zaman aralığına yerleştirmekle görevlidir. Komisyon üyesi olarak giriş yapıldığında öğretim üyeleri, ders, şube, ders birleştirme ve takvim işlemleri yapılabilirken; yönetici yetkisine sahip olan kullanıcıların dönem ve sınıf ekleme gibi yetkileri de bulunmaktadır.

DÇP kullanıcı tiplerine göre Komisyon üyeleri sadece kendi hesapları ile ilişkilendirilmiş fakülte bölümlerine ve enstitü programlarına müdahalede bulunabilir. Yöneticiler ise tüm müfredatlara erişme yetkisine sahiptir. Tüm komisyon üyeleri yönetici tarafından bölümlerine tanımlanan hesaplar ile giriş yapabilmektedir. Giriş sayfası Şekil 1'de gösterilmiştir.

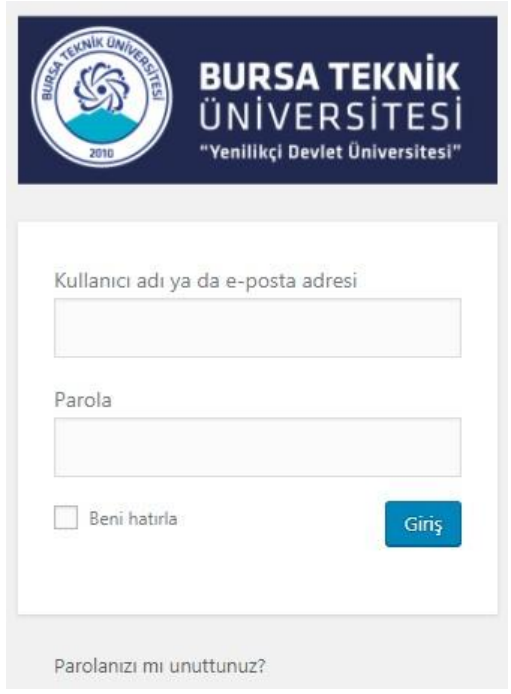

Şekil 1. Giriş sayfası

\subsection{Anasayfa}

DÇP'ye giriş yaptıktan sonra gelen karşılama ekranında kullanıcının, üzerinde yetki sahibi olduğu müfredatlar ve modüller listelenmektedir. Kullanıcı girişlerine göre anasayfalar Şekil 2'de gösterilmiştir.

\subsection{Uygulama modülleri}

DÇP uygulaması çeşitli modüllerden oluşmaktadır. Bu modüller sayesinde farklı işlemler gerçekleştirilebilmektedir.

\subsection{1 Öğretim üyesi modülü}

Komisyon üyeleri tarafından da bölümlerinde yer alan öğretim üyelerinin isim ve soy isim bilgilerinin kayıt edildiği ve listelenebildiği bu modül sayesinde üniversitedeki tüm öğretim üyelerinin haftalık ders programlarına kolaylıkla erişilebilmektedir. Eklenmiş olan tüm öğretim üyelerinin isimleri liste halinde görülebilmektedir. Modülün öğretim üyesi ekleme kısmı Şekil 3'te gösterilmektedir. Öğretim üyesi kaydı yapılırken girilen isim ve soyisimdeki karakterler büyük harflere dönüştürülmektedir. Ayrıca mükerrer girdilerin engellenmesi için veritabanında bu bilginin zaten var olup olmadığ kontrol edilmektedir.

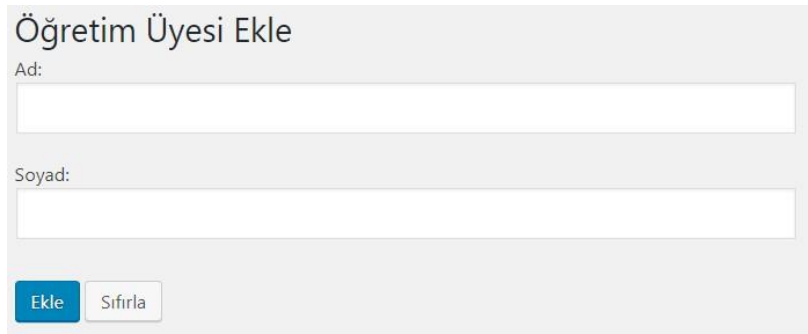

Şekil 3. Öğretim Üyesi Ekleme
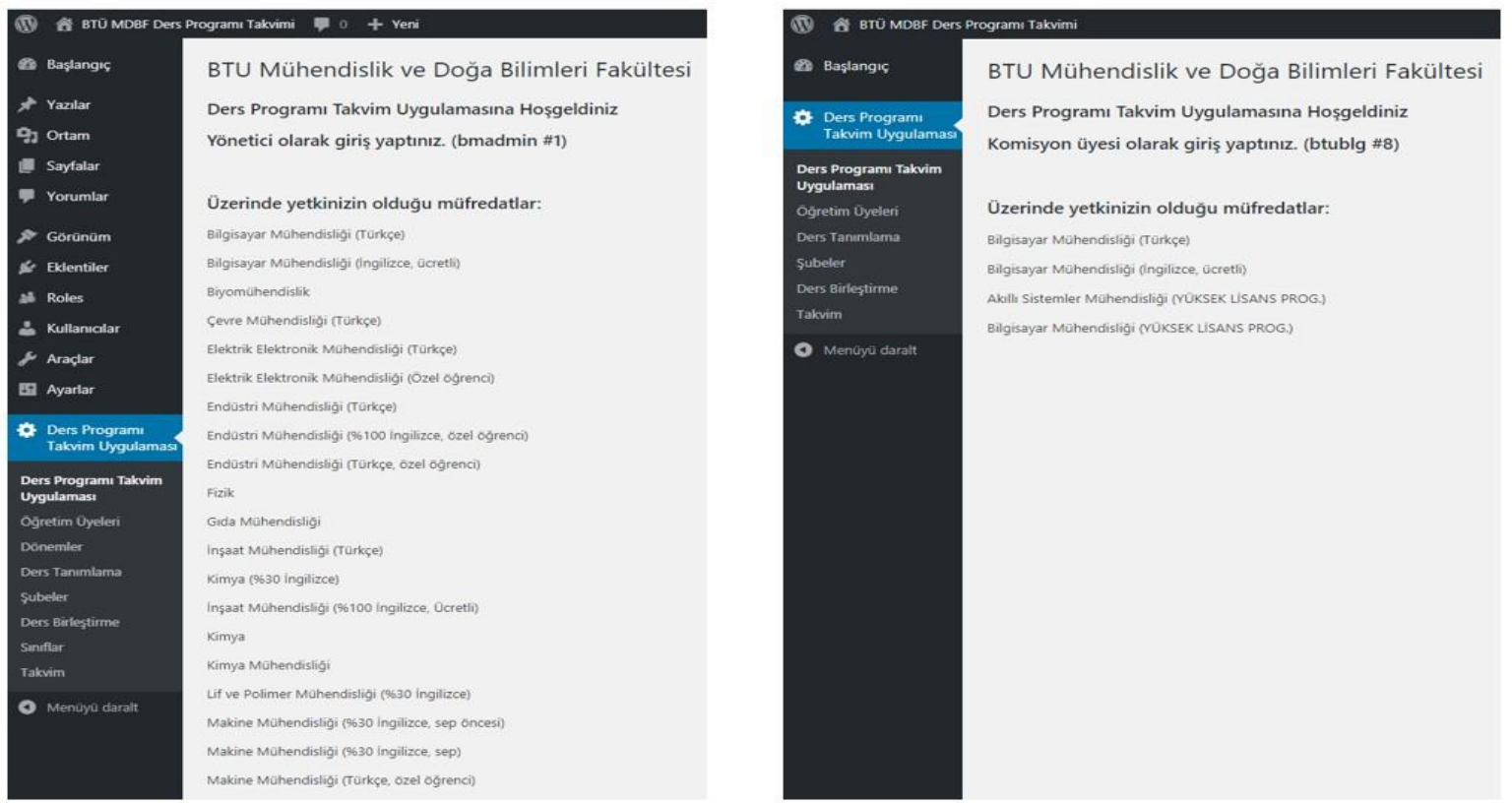

Şekil 2. Anasayfa 
Üniversitenin eğitim döneminin tanımlamasının yapıldığ modüldür. Yönetici yetkisi ile tanımlama yapılmaktadır. Dönem tanımlama sayfası Şekil 4'te sunulmuştur. Derslerin takvime eklenebilmesi için en az bir şubeye sahip olması gerekmektedir. Şubeler ise dönem bilgisiyle ilişkili olarak oluşturulmaktadır. Her bir şube bir döneme aittir; bir dersin farklı dönemlerde takvime eklenebilmesi için yeni dönemle ilişkili bir şube oluşturulmalıdır. Bu dönem bilgileri yönetici yetkisine sahip kullanıcılar tarafindan "Dönemler" sayfasında oluşturulup düzenlenmektedir.

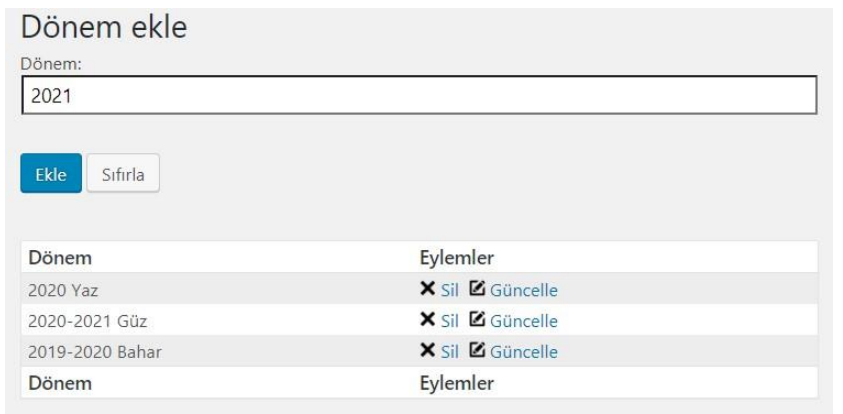

Şekil 4. Dönem tanımlama

\subsubsection{Ders tanımlama modülü}

Komisyon üyesi yetkisine sahip kullanıcılar yetkili oldukları bölümler/müfredatlar için dersleri tanımlamaktadırlar. Ders tanımlamaları bölüm/müfredat ile ilişkili olarak yapılmaktadır. Farklı bölümlerde açılan aynı dersler, aynı ders kodlarına sahip olsalar bile, ayrı ayrı tanımlanmalıdır. Ders tanımlaması yapılırken dersin teorik veya uygulama dersi olduğunu belirten tip bilgisi de istenmektedir. Ders tanımlama sayfası Şekil 5'te sunulmuştur. Ders kodu ve dersin adı tanımlandıktan sonra dersin kaçıncı sınıfta verileceği, kontenjan, tip ve bölüm bilgisi seçildikten sonra ders tanımlaması tamamlanmış olur.

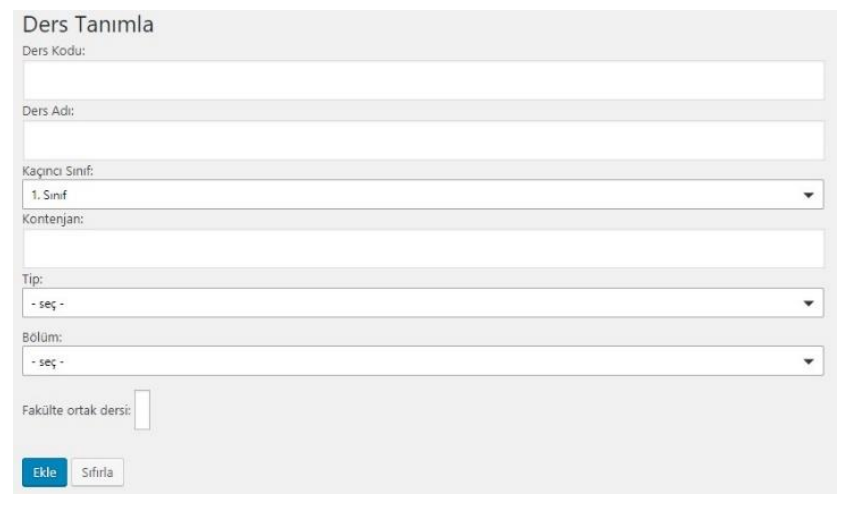

Şekil 5. Ders tanımlama

\subsection{4 Şube ekleme}

Ders tanımlama modulünde tanımlanan her dersin takvime işlenebilmesi için şubesinin açılması gerekmektedir. Birden fazla öğrenci grubu şeklinde yapılacak derslerin ise o kadar sayıda şubesi açılmalıdır. Şubesi açılmayan dersler, tanımlanmış olsa dahi takvime işlenememektedir. Şube tanımlama sayfası Şekil 6'da gösterilmiştir. Şubesi açılacak dersin dönem, hangi bölüme ait olduğu ve ismi seçildikten sonra otomatik olarak oluşturulan şube ismiyle tanımlama yapılmaktadır.

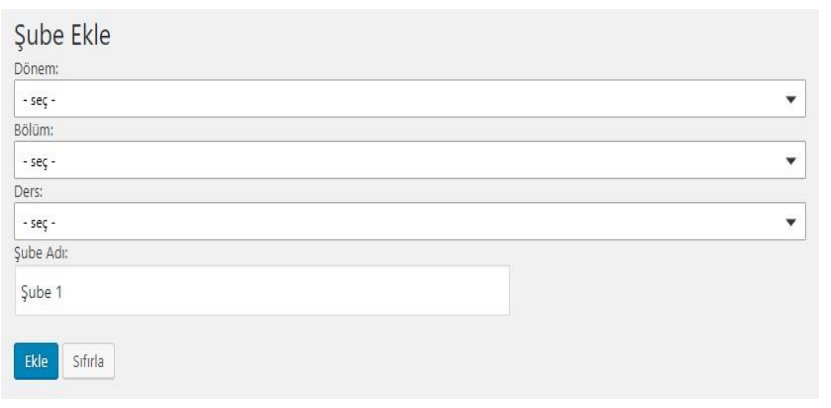

Şekil 6. Şube ekleme

\subsubsection{Ders birleştirme}

Ders programları hazırlanırken öğretim üyesi ve derslik çakışmalarının önüne geçilmelidir. DÇP'nin geliştirilmesindeki en önemli amaçlardan biri de bu çakışmaların tespit edilip, komisyon üyelerinin uyarılmasını sağlamak ve bu probleme her çeşit fakülte ve ders yapısı ile uyumlu olacak şekilde çözüm üretmektir.

DÇP, takvime yeni bir ekleme yapılırken veya takvimde var olan bir girdi düzenlenirken çakışmaları tespit edip, işlemi durduracak şekilde tasarlanmıştır. Fakat farklı bölümlerde aynı öğretim üyesi tarafından birleştirilerek verilecek farklı kodlu dersler için istisnai bir durum söz konusudur. Birleştirilecek bu dersler "Dersleri Birleştir" modülünde komisyon üyeleri tarafından gerçekleştirilir (Şekil 7).

Birleştirilen bir dersi sehven veya zorlayarak, farklı bir zamana, sınıfa ve öğretim üyelerine atamalarına ihtimal vermemek için derslerin ait olduğu bölümlerin komisyon üyeleri arasında onaylama işlemi yapılması gerekmektedir (Şekil 8). Komisyon üyeleri sadece kendi bölümlerine ait olan dersleri onaylayabilmektedirler. Bir onaylama işlemi gerçekleştikten sonra ilgili ders birleştirme girdisindeki diğer

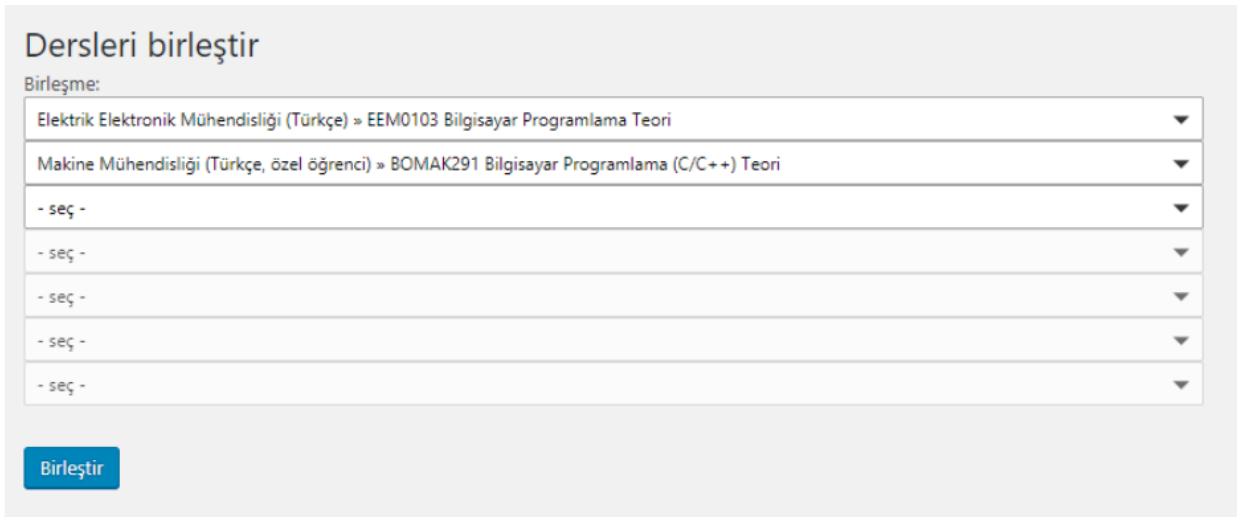

Şekil 7. Ders birleştirme 
dersler onaylanan dersin takvimde bulunduğu zaman dilimine

Şekil 9. Sınıf ekleme eklenebilmektedir.

\begin{tabular}{|c|c|c|c|c|c|c|c|}
\hline Ders 1 & Eylemler & Ders 2 & $\begin{array}{l}\text { Ders } \\
2 \\
\text { Onay }\end{array}$ & Ders 3 & $\begin{array}{l}\text { Ders } \\
3 \\
\text { Onay }\end{array}$ & Ders 4 & $\begin{array}{l}\text { Ders } \\
4 \\
\text { Onay }\end{array}$ \\
\hline $\begin{array}{l}\text { Makine Mühendisliği (Mühendislikk } \\
\text { tamamlama) } \\
\text { MAT0291 Diferansiyel Denklemler } \\
\text { Teori }\end{array}$ & $\mathbf{x}_{\text {Sil }}$ & $\begin{array}{l}\text { Makine Mühendisliği ( } \% 30 \\
\text { Ingilizce, sep) } \\
\text { MAT0291 Diferansiyel } \\
\text { Denkemler Teori }\end{array}$ & $\nabla$ & $\begin{array}{l}\text { Makine Mühnendisliği ( } 930 \\
\text { ingilizce, sep öncesi) } \\
\text { MAT291 Diferansiyel } \\
\text { Denkiemler Teori }\end{array}$ & $v$ & $\begin{array}{l}\text { Makine Mühendisliği } \\
\text { (Türkçe, özel ögrrenci) } \\
\text { BOMAT291 Diferansiyel } \\
\text { Denklemler Teori }\end{array}$ & $\checkmark$ \\
\hline $\begin{array}{l}\text { Elektrik Elektronik Mühendisliği } \\
\text { (Türkçe) } \\
\text { EEM0103 Bilgisayar Programlama } \\
\text { Teori }\end{array}$ & $\mathbf{x}_{\text {Sil }}$ & $\begin{array}{l}\text { Makine Mühendisliği (Türkçe, özel } \\
\text { ögrenci) } \\
\text { BOMAK291 Bilgisayar } \\
\text { Programlama (C/C++) Teori }\end{array}$ & $\nabla$ & & & & \\
\hline $\begin{array}{l}\text { Elektrik Elektronik Mühendisliği } \\
\text { (Türkçe) } \\
\text { EEM0103 Bilgisayar Programlama } \\
\text { Lab/Uyg }\end{array}$ & $x_{\text {sil }}$ & $\begin{array}{l}\text { Makine Mühendisliği (Türkçe, özel } \\
\text { ögrenci) } \\
\text { BOMAK291 Bilgisayar } \\
\text { Programlama (C/C++) Lab/Uyg }\end{array}$ & $\nabla$ & & & & \\
\hline $\begin{array}{l}\text { Bilgisoyar Mühendisliği (ingilizce, } \\
\text { ücretli) } \\
\text { PHY101 Physics I Teori }\end{array}$ & $\mathbf{x}_{\text {Sil }}$ & $\begin{array}{l}\text { Elektrik Elektronik Mühendisliği } \\
\text { (Özel ögrenci) } \\
\text { DDPHY0101 Physics I Teori }\end{array}$ & $\nabla$ & $\begin{array}{l}\text { Endüstri Mühendisliği ( } \% 100 \\
\text { ingilizce, özel ögrenci) } \\
\text { PHY101 Physics I Teori }\end{array}$ & $\nabla$ & $\begin{array}{l}\text { Inşaat Mühendisliği ( } \% 100 \\
\text { Ingilizce, Ücretli) } \\
\text { PHY101 Fundamentals of } \\
\text { Physics Teori }\end{array}$ & $\nabla$ \\
\hline $\begin{array}{l}\text { Bilgisayar Mühendisliği (ingilizce, } \\
\text { ücretli) } \\
\text { PHY101 Physics I Lab/Uyg }\end{array}$ & $\mathbf{x}_{\text {Sil }}$ & $\begin{array}{l}\text { Elektrik Elektronik Mühendisliği } \\
\text { (Özel ögrenci) } \\
\text { DDPHY0101 Physics I Lab/Uyg }\end{array}$ & $\nabla$ & $\begin{array}{l}\text { Endüstri Mühendisliği ( } \% 100 \\
\text { ingilizce, özel ögrenci) } \\
\text { PHY101 Physics I Lab/Uyg }\end{array}$ & $\nabla$ & $\begin{array}{l}\text { inşaat Mühendisliği ( } 96100 \\
\text { ingilizce, Ücretli) } \\
\text { PHY101 Fundamentals of } \\
\text { Physics Lab/Uyg }\end{array}$ & $\nabla$ \\
\hline $\begin{array}{l}\text { Makine Mühendisliği (9630 } \\
\text { Ingilizce, sep öncesi) } \\
\text { MAK301 Akışkanlar Mekaniği } \\
\text { Teori }\end{array}$ & $\mathbf{x}_{\text {Sil }}$ & $\begin{array}{l}\text { Makine Mühendisliği (Türkçe, özel } \\
\text { ögrenci) } \\
\text { BOMAK301 Akışkanlar Mekaniği } \\
\text { Teori }\end{array}$ & $\nabla$ & $\begin{array}{l}\text { Makine Mühendisliği (\%30 } \\
\text { ingilizce, sep) } \\
\text { MAK0301 Akışkanlar Mekaniği } \\
\text { Teori }\end{array}$ & $\nabla$ & $\begin{array}{l}\text { Makine Mühendisliği } \\
\text { (Mühendislik tamamlama) } \\
\text { MAK0301 Akısckanlar } \\
\text { Mekaniği Teori }\end{array}$ & $\nabla$ \\
\hline
\end{tabular}

Şekil 8. Birleştirilen derslerin listelenmesi ve onaylanması

\subsubsection{Sinıf ekleme}

Ders işlemeye elverişli sınıfların kaydının yapıldığı bu bölümde sınıf ismi, sınıf kapasitesi ve aktiflik yanında; sınıfta işlenebilecek dersin türü de seçilebilmektedir (Şekil 9). Böylece ders türlerine göre sınıf seçimi daha kolay hale gelmektedir. Ayrıca eğitim kurumundaki tüm sınıf listesi de modülde görülebilmektedir.

\subsubsection{Takvim}

Dersler, haftalık programa uygulamanın "Takvim" modulünden yerleştirilmektedir. Takvime yerleştirilecek olan dersin dönemi, hangi müfredata ait olduğu, ismi, şubesi ve öğretim üyesi seçildikten sonra hangi gün, hangi saatlerde arasında ve hangi sınıfta yapılacağı girildikten sonra takvime yerleştirilebilmektedir. Fakat ders yerleştirme esnasında belirtilen gün ve saat aralığı içerisinde öğretim üyesi, şube veya sınıftan en az biri dolu ise yerleştirme işlemi yapılamamakta ve kullanıcıya "Ders eklenemedi. Öğretim üyesi, sınıf veya grup çakışmasını kontrol edin" şeklinde çakışma uyarısı verilmektedir.

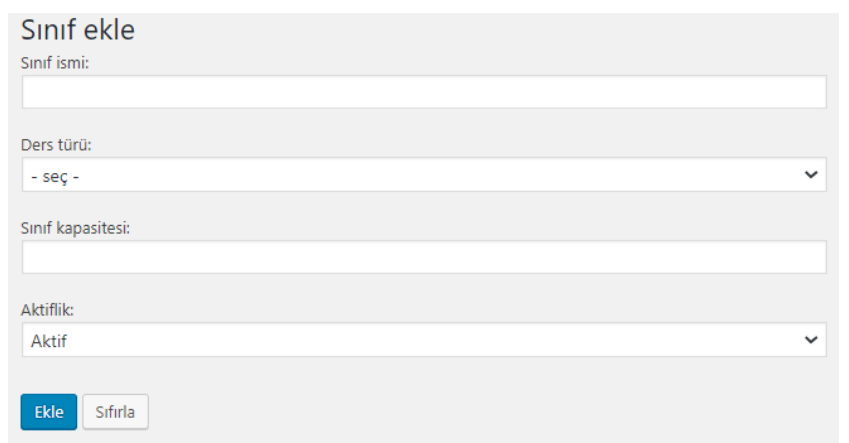

sunulmaktadır. "Filtreleme" kısmında dönem, bölüm, öğretim üyesi, sınıf veya dersliğe göre filtreleme yapılarak gösterilebilmektedir. Şekil 10 'da Bilgisayar Mühendisliği Türkçe bölümünün 2020 Yaz döneminde 1. sınıflarının ders programı görüntülenmiştir.

Takvime eklenen derslerin listesi veya haftalık program olarak tablosu *.xlsx formatında indirilebilmektedir. Takvim sayfasında görüntülenen tablo için uygulanan filtre kuralları indirilen Excel dosyaları için de geçerlidir (Şekil 11). 


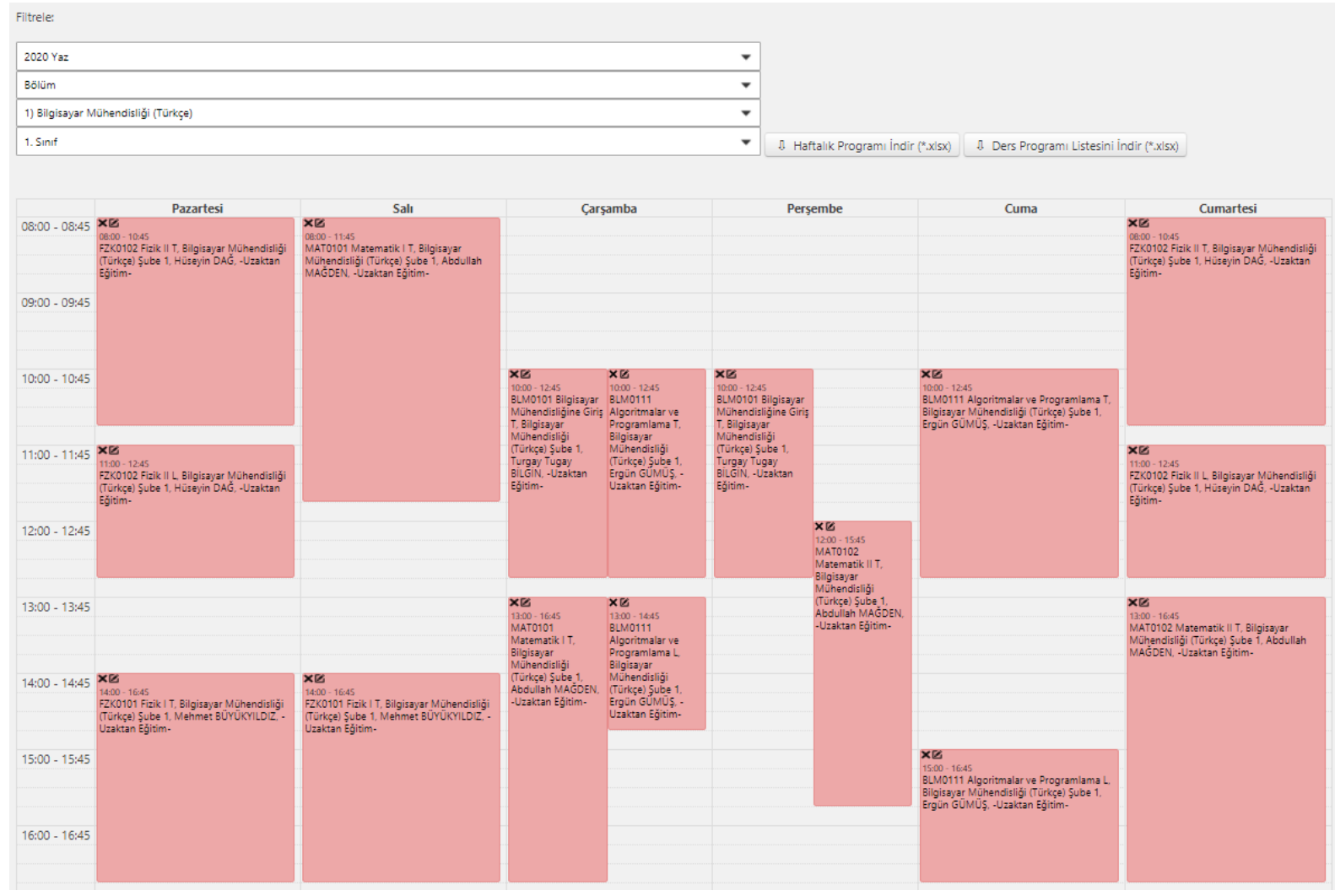

Şekil 10. Ders programı takvimi

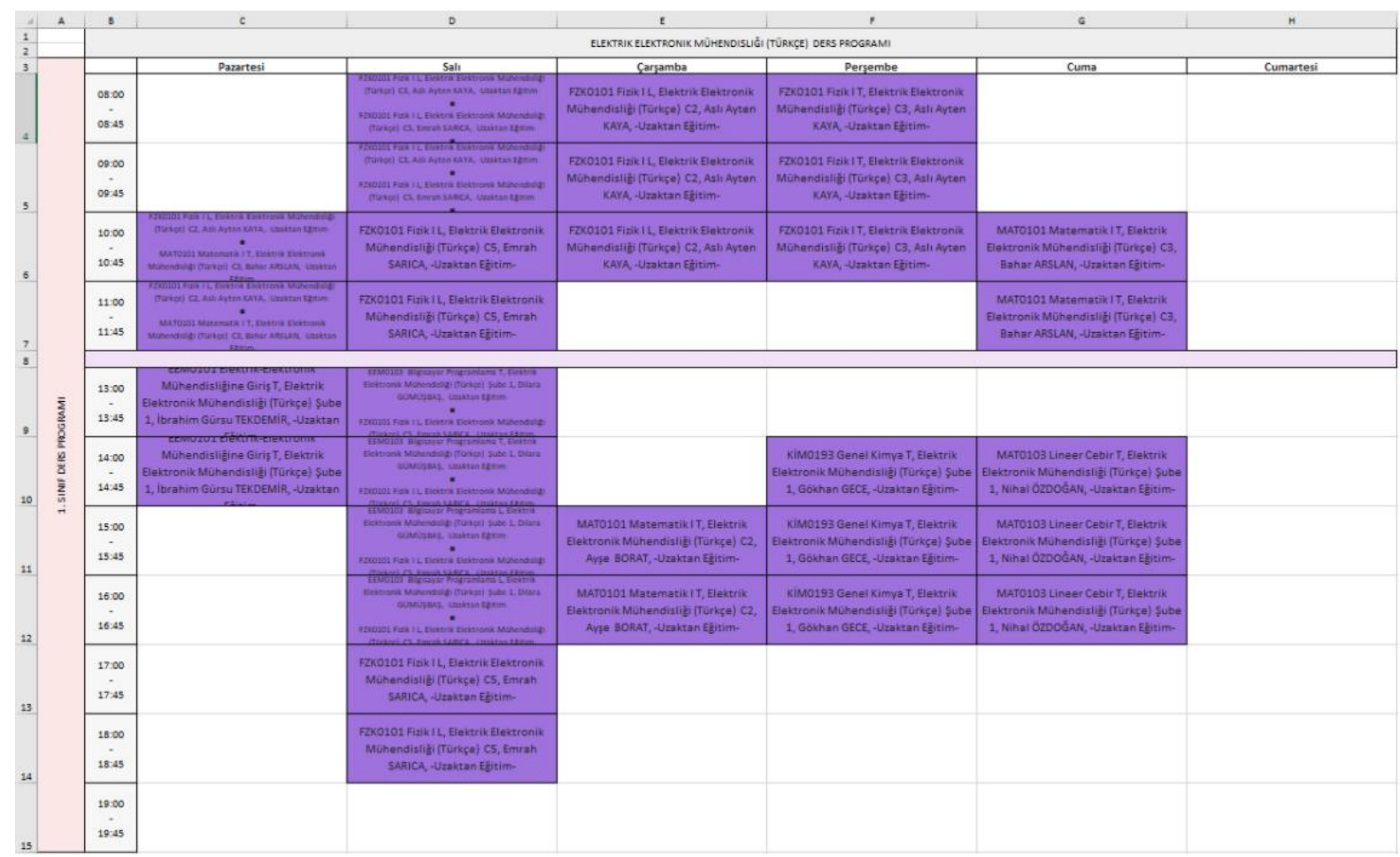

Şekil 11. Ders programlarının Excel çıktısı

\subsubsection{Veritabanı mimarisi}

DÇP'de takvime yerleştirilen dersler şubelerle, öğretim üyeleriyle ve sınıflarla ilişkilidir. Şubeler, dönem ve ders ile bağlantılıdır. Derslerin bilgisi ise bölüm ile ilişkilendirilmiştir. Bu şekildeki yapı sayesinde her dönem ders ve şube dağılımı değişen fakülteler için kullanım kolaylığı sağlanmıştır. Ayrıca bu sayede bir bölümden diğer bölüme verilen derslerin ve birden fazla bölüm için birleşen ortak derslerin sisteme tanımlanması mümkün hale gelmiştir.

Sınıf tablosundaki sütunlar aşağıdaki gibidir (Şekil 12): classroomID: Sınıflar için ID değerlerinin tutulduğu birincil anahtar, 
name: Sinıf ismi,

type: Sınıf, laboratuvar, amfi vb. sınıf türlerinin String biçiminde tutulduğu alan,

is_available: Sınıfın uygun olup olmadığını belirten alan, capacity: Sınıfın en fazla kaç öğrenci ile işlenebilir olduğunu gösteren alandır.

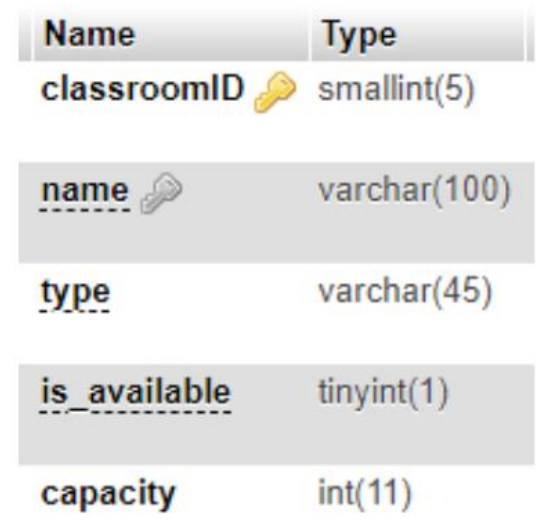

Şekil 12. Sınıf bilgilerinin tutulduğu tablonun yapısı

Bölümler tablosunun alanları (Şekil 13):

departmentID: Bölümler için benzersiz ID numarası olan birincil anahtar sütunu,

name: Bölüm/program isminin tam halinin tutulduğu alan, authUserID: Bölüm/program üzerinde yetkisi olan komisyon üyesinin Wordpress kullanıcı ID numarası,

color: Takvimde bölümlerin ayrımını kolaylaştırabilmek için belirlenen rengin alanı,

canEdit: Bölümün programa ders eklemeye/programdaki dersi düzenlemeye açık olup olmadığını belirten alan, programLevel: Bölümün seviyesini gösteren alandır (0: lisans bölümü, 1: yüksek lisans programı, 2: doktora programı.

\begin{tabular}{|ll}
\hline $\begin{array}{l}\text { Name } \\
\text { departmentID }\end{array}$ & $\begin{array}{l}\text { Type } \\
\text { int(10) }\end{array}$ \\
\hline name & varchar(64) \\
\hline authUserID & bigint(20) \\
\hline color & varchar(10) \\
\hline canEdit & tinyint(1) \\
\hline programLevel & tinyint(1) \\
\hline
\end{tabular}

Şekil 13. Bölüm bilgilerinin tutulduğu tablonun yapısı

Ders birleştirme bilgilerinin bulunduğu tabloda oluşturulan her birleştirme kuralı için benzersiz bir numara jointID sütununa atanır. Kuralı ekleyen kullanıcının Wordpress ID numarası ise userid alanında tutulur. 13 sütundan 7 tanesi birleştirilen derslerin ID numaralarını bulundururken, kalan 6 sütuna bu derslerin ait oldukları bölümlerin yetkili komisyon üyesinin bu birleştirme kuralına onay verip vermediği bilgisi kaydedilir. İlk dersi ekleyenin ders üzerinde yetkisi olan bir kullanıcı olması gerektiğinden bu ders için bir onay alanına gerek yoktur.
Takvime yerleştirilen dersler öncelikle bir tabloya kaydedilir. Ardından ilişkisel veritabanından kolay veri çekebilmek için oluşturulmuş bir "View" ile dönem, zaman çizelgesi, ders, şube, sınıf, öğretim üyesi ve bölüm/program bilgilerine erişilmektedir.

Takvime eklenen derslerin bilgilerinin tutulduğu tablonun sütunları şu şekildedir:

lectureID: Zaman çizelgesindeki dersin birincil anahtar olan benzersiz ID numarasi,

groupID: Derse tanımlanmış şubenin ID numarası,

classroomID: Hangi dersliğin seçildiğini gösteren ID numarasi,

teacherID: Öğretim üyesine ait ID numaras1,

start: Dersin zaman çizelgesindeki başlangıç zamanı,

end: Dersin zaman çizelgesindeki bitiş zamanı,

description: Takvim çıktısı resmi işlemler için liste halinde alındığında ilgili satırda yazacak olan açıklama metni (opsiyonel),

userid: Dersi zaman çizelgesine ekleyen kullanıcının Wordpress ID numarasıdır.

\section{Bulgular ve Tartışma}

DCP her dönem kullanıldığı kurumun ihtiyaçlarına göre revize edilmektedir. Her yarıyıl öncesi hazırlanan ders programları DÇP üzerinden kontrol edildiğinde ortak derslerin çakışmaya neden olmadan düzenlenebildiği ve zamandan büyük oranda tasarruf sağlandığı görülmüştür. DÇP ile fakültede yer alan bölümler, defalarca kontrol etmeye ve birimler arası haberleşmeye gerek kalmadan hazırlanabilir hale gelmiştir.

DÇP, yapısı sayesinde kolaylık ve hızın yanında esneklik de sağlamaktadır. Bir merkezden üretilen ve bütün fakülte bölümlerini kapsayan ders programlarının aksine DÇP üzerinde, bölümler ortak dersler konusunda kendi ihtiyaçlarına da uygun olarak fikir birliği oluşturabilmekte ve buna rağmen bürokratik süreç kolayca idare edilebilmektedir. Her bölüm, ortak dersler dışında kalan dersleri için uygun zaman, öğretim elemanı ve derslik seçme özgürlüğüne sahip olmaktadır.

Ders çizelgeleme sürecinin sonrasında ihtiyaç duyulabilecek muhtemel düzenleme talepleri de DÇP ile fazladan işleme gerek olmadan kontrol edilebilmektedir. Düzenleme sırasında oluşan bir aksilik veya çakışma sistemin işlemi kabul etmemesine sebep olmaktadır. Uyumlu düzenlemeler ise başka gözlemler yapmaya gerek kalmadan anında kullanılabilir hale gelmektedir. Ayrıca bu sayede, bir bölümün, dersliğin, öğretim üyesinin veya özellikle bir dersin haftalık programı otomatik olarak güncellenmekte ve doğrudan gerekli birimlere bildirilebilmektedir.

\section{Sonuc}

$\mathrm{Bu}$ çalışmada bir üniversitenin özellikle mühendislik bölümleri için oluşturulan ders programlarını ortak bir platformda sunmak için UniTimetable eklentisinden referans alınarak bir Wordpress eklenti uygulaması olan DÇP geliştirilmiştir. Açık kaynak yazılım araçlarıyla geliştirilen bu uygulama dersleri tanımlamak için öğretim üyelerini, sınıflarını, ders bilgilerini ve öğrenci gruplarını içermektedir. Çeşitli filtrelemelerle her bir ögretim üyesinin ders programı bilgilerine ulaşabilmektedir. Bunun yanında her bir sınıfın doluluk çizelgesi ya da istenilen bölümlerin istenilen sınıflarının ders programlarına rahatlıkla ulaşılabilmektedir. Fakültede birleştirilen dersler için bölüm komisyon üyeleri koordineli şekilde ders, sınıf ve zaman ayarlaması yapabilmektedir. Ders programı oluşturulurken bu uygulama sayesinde sınıf, öğretim üyesi veya ders çakışmaları tespit 
edilebilmektedir.

Eklentinin kodları Bursa Teknik Üniversitesi Bilgisayar Mühendisliği Github hesabında açık kaynaklı olarak bulunmaktadır. Kodlara https://github.com/btu-cse/btu-mdbfdcp linki ile ulaşıllabilir.

\section{Teșekkür}

Çalışma kapsamında, kaynaklarından yararlandığımız bilim insanlarına ve kurumlara teşekkür ederiz.

\section{Kaynaklar}

Burke, E. K., Elliman, D. G., \& Weare, R. (1994). A university timetabling system based on graph colouring and constraint manipulation. Journal of research on computing in education, 27(1), 1-18.

Fragulis, G. F., Lazaridis, L., Papatsimouli, M., \& Skordas, I. A. (2018, September). ODES: an online dynamic examination system based on a CMS Wordpress plugin. In 2018 South-Eastern European Design Automation, Computer Engineering, Computer Networks and Society Media Conference (SEEDA_CECNSM) (pp. 1-8). IEEE.

Poddar, N., \& Mondal, B. (2018). An Instruction on Course Timetable Scheduling Applying Graph Coloring Approach. International Journal of Recent Scientific Research, 9(2), 23939-23945.

Rao, M. S., Prasad, K. L., \& Anusha, P. (2019). Automatic Timetable Generation Using PBIL Algorithm. iManager's Journal on Information Technology, 8(2), 31.

Kokkoras, F., \& Roussos, A (t.y).UniTimetable, Erişim adresi https://wordpress.org/plugins/unitimetable/\#description 